\title{
Identifying characteristics of parental involvement: Aesthetic experiences and micro- politics of resistance in different schools through ethnographic investigations
}

Begoña Vigo-Arrazola* https://orcid.org/0000-0001-9734-8596 and Belén Dieste-Gracia http://orcid.org/0000-0002-7262-896X

Department of Educational Sciences, Faculty of Education, University of Zaragoza, Zaragoza, Spain;

*mbvigo@unizar.es

Begoña Vigo-Arrazola is Associate Professor in the Faculty of Education at the University of Zaragoza, Spain. She is head of the research group in Education and Diversity. Her research interests and publications are in the field of educational ethnography, inclusive education, parental involvement, teacher education and rural schooling.

Belén Dieste-Gracia is Assistant Professor in the Faculty of Education at the University of Zaragoza, Spain. She is a member of the research group in Education and Diversity. Her research interests and publications are in the field of inclusive education, participation of families in school, education for global citizenship and teacher training. 


\begin{abstract}
This article focuses on the relevance that aesthetic practices play extending parental involvement and influence in school contexts in Spain. One rural, one urban and one peri-urban school have been included in the research. Participant observation and interviews were the main means of data production. In the results all the different schools promoted parents' participation. However, differences in aesthetic practices and experiences were found. Parental involvement was developed in schools in different ways in relation to local contextual conditions and the salient characteristics of the geographic spaces the schools belonged to. Practical aesthetic knowledge produced multiple strategies of action.
\end{abstract}

Keywords: ethnographic methods, parental involvement, urban spaces, rural spaces, peri-urban spaces, aesthetic practices. 


\section{Introduction}

There has been a great deal of research on parental involvement in school (Tveit 2014), linked often to education policy, the educational achievement of pupils, and the quality of education generally (Edwards and Alldred 2000). However, creating parental and family inclusion is still complex and notoriously difficult to evaluate the success of, not the least in culturally and socioeconomically diverse school contexts (Bouakaz 2007; Vigo-Arrazola and Soriano-Bozalongo 2015; Vigo-Arrazola and Dieste-Gracia 2017; Vigo-Arrazola and Dieste-Gracia 2019) where specific cultural and inter-cultural differences and tensions that may affect the ways parents engage with their children's schools can go un-noticed and unacknowledged (Bouakaz 2007).

Based on ethnographic research, in the present article we have analysed how family participation and involvement are organised and motivated in contextually and geo-spatially different schools and what seems to influence these practices. Key questions are how do different spatial characteristics affect aesthetic experiences and interplay with the involvement of families and teachers (Bouakaz 2007) and how might this contribute to develop some resistance in a hegemonic school that traditionally has differentiated families and teachers. When conducting the research we have considered individuals to be the artists of their own lives, who combine experiences and perceptions to form practices that can destabilize dominant understandings of the world and rebuild them as more socially just orientations appropriate to school sites. Individuals are understood as struggling with the things that are affecting them, in ways that alter their way of perceiving and understanding the world. 


\section{Theoretical frame and previous research}

In line with the above we are following Foucault's (2009) idea of resistance and his notion of a microphysic's of power (Foucault, 1991) where individuals develop in interaction with the structures created in society and from experiences and/of social practices and aesthetic experiences there. They are in this way actively constituting the medium through which their personal habitus is produced and the quintessential aesthetic aspect introduced by Foucault (2009) here is important as is his notion of power. Where there is power, there is also resistance. Resistance is created from within the relations of power, fields of knowledge, bodies, societies, and processes of normalization, where we constitute ourselves as subjects that act as moral agents on others.

When considering these aesthetic practices of subjectivation, we are pointing to three things that seem to be specifically important. The first is that social groups and individuals are positioned in distinctly different ways in different places in relation to the ebbs and flows of the current political economy of signs, privileges, materials and possibilities (Foucault 1991). The second is that these things have significant influence but can be still be tempered by political regulation (ibid.). Power and politics are significant and different social groups in different places are able to form different relationships to the local place and to schooling/educational processes within it from the aesthetic interpretations they make (Foucault 2009).

Our research has utilised Foucault' microphysics in relation to research on parental and family involvement in school in particular for groups that are currently disadvantaged, which has previously been identified as often quite difficult (Bouakaz 2007; Garreta and Llevot 2011), but also very significant for pupil educational performance levels (Esteban-Guitart, Oller, and Vila 2012; Tveit 2014). Bouakaz (2007) showed for instance that the development of more of a 
community spirit to encourage, incorporate and involve parents and community members more actively was quite difficult and complex at times, and was best facilitated through dialogue, not only with parents but also between parental groups. Along with Crozier and Davies (2007), he was especially interested in seeing the ways in which educators interacted with the parents and the extent to which these interactions were truly collaborative and made use of Edwards and Alldred (2000) identified that they often weren't and that interactions with parents can differ significantly in relation to the social locations of the home as the teacher's professional habitus (her professional aesthetic) often functions in line with the dominant institutional doxa to marginalise relationship work with some groups and to initiate, sustain and encourage it in others (Bergnehr 2015). Thus, on the one hand, the structure between parents is accepted by teachers and they (teachers) tend to develop interactions with the structures created in the society reinforcing the asymmetry. On the other hand, teachers can also act in relation to a professional ethics that constitutes them and parents as moral agents carrying out new ways of doing things.

Bergnehr (2015) demonstrates that significant contradictions can often be uncovered between policies of parental involvement and practices. Schools can be exclusionary in the ways they create and manage involvement. Teachers may involve parents, but they can also be very selective about this and will control this participation as an acknowledged cultural activity that is called for, but that shouldn't unduly affect their own professional plans, actions and values (Bergnher 2015). In these cases, even when they are involved, lower social class parents and families are often put into a disadvantaged situation considering how they and their potential contributions are valued, and this can also become difficult to hide from them, and equally difficult for them to hide from (Bouakaz 2007). Pointing out this foundation of practice, schools and classrooms are not neutral spaces but rather contested aesthetic arenas within which the 
representation of marginalized groups is dependent on the willingness and capabilities of teachers to experience and enact a challenge toward historical givens and raise awareness of existing images and the impact they have in order to generate new visions and new ways of being and working.

We point out the aesthetic experience of subjectivation to rethink and to rebuild practices and interactions in these ways and along these lines. We argue that the construction of the subject involves the exposure of bodies and minds to a power and a knowledge that traps, monitors and punishes or, alternatively frees empowers and rewards (Bergnehr 2015). This is the construction of subjectivity and it is achieved through the exercise of reflexive indocility against what has been imposed on us. However, challenging historical dogma and territorial stigmatization in these ways is more problematic than is often recognised (Beach 2017), and we argue too that there is a close connection between space, place and the construction of social relations, practices, meaning and spatial identities in this respect. In a context where research shows how teachers try to involve parents, but how lower- social class parents and families are also often put into a disadvantaged situation (ibid.), we try to identify what concepts are developed and/or used, and what innovations, grafts and strategies to accomplish change as a force that pushes the culture of some schools to develop a logic of opposition can be found in different schools.

\section{The research and research sites}

This study has been conducted in the decentralised Spanish school system. Decentralisation began in Spain in 1979 when the different Communities (Cataluña, Galicia, Andalusia, etc) were granted some autonomy from the state curriculum for local content. However, through the most recent general common education act of 2013 common exams have been reintroduced with this re-emphasising state jurisdiction and control over official knowledge. Education is provided 
through pre- and elementary schools, secondary and upper-secondary schools, and vocational and special schools. Schools are generally public, but there is nowadays also a high number of private institutions that are partially funded by the state and partially fee paying (Escardíbul and Villarroya 2009).

Our focus is on state elementary education for children from 6 to 12 years. This is normally divided into six grades and in all of them the collaboration and participation of families is legislated in order to contribute to children achieving the objectives of the school. This has been the case since the Constitution in 1978 (article 27) that charged the public authorities with guaranteeing the right to education with the 'effective participation of all affected sectors', including parents. The participation of the families in schools in terms of information and coordination is an important aspect to achieve school success according to this legislation.

The article has been produced from research that was conducted in the academic year 2011-12 as part of a national research project on 'Discourses and practices of family participation in compulsory education'. Both Elementary and Secondary schools were included as were 12 researchers from research teams in Aragon, Cataluña, Islas Baleares and La Rioja. The project began by conducting 47 interviews with politicians and labour union representatives to inquire about parental involvement in schools and to ask for examples of schools from each region that actively encouraged this involvement and that they felt showed success in this venture. Thirty schools were identified and contacted. They were from different types of catchment in terms of class and ethnic composition and a mix of rural, urban and peri-urban schools was included.

The national project was an IT-enhanced, multi-centre and multi-sited research project that initially lasted for two years. In our part of it, in Aragon, it involved two rural and six urban 
schools. Three of them were elementary (age 6-12) schools and it is these three schools that are considered in the article. They were chosen on the basis of comments about them in interviews and because they came from different types of catchment area (one urban, one rural and one periurban). Further details about them are given in the table 1 below.

[near here] Table 1: Salient summarizing demographic details and main characteristics of the schools

\section{Methods}

Ethnographic fieldwork was employed in our research together with interviews to produce the bulk of the data for answering the general research question about how different actions and experiences produce different possibilities for and types of parental involvement. Three researchers carried out the studies: one at each of the three schools. They used multiple methods to build diverse forms of data, but in line with Troman (2006), they also recognised that the researcher and her reflections form the main research instrument. Participant observation was made three times a week during the school year of 2013-2014 and in addition the use of virtual platforms and social media were also studied at the three schools, as a way to help us to grasp parental involvement in relation to both offline and online activities. Semi-structured interviews were made with teachers, headteachers, parents/guardians and administrators. These were recorded and transcribed and the correctness of the transcriptions were checked with the interviewees through forms of respondent validation and there was an intention to try to create as active space and role for informants beyond those of object or audience (Denzin 2018). Teachers and parents were to enter in the research process as responsible subjects, questioning the aim of the research, representing their social world, and re-appraising methods of data collection, analysis and reporting (Fox and Alldred, 2018). The conventional dualism between researcher and research subjects was to be challenged as was the 
tendencies in ethnographic research to focus on relationalities that extend and/or enhance the boundary between people and objects (Tummons and Beach in this special issue). The commitment was toward an analysis of how the two are constituted within a shared system of actants from a perspective that recognises the connectivity, contagion, fusion, relationality and entanglement between humans and objects as social phenomena that are not independent of the context in which they occur (ibid.).

\section{Analysis}

The multi-sited character of ethnography (Eisenhart 2017) allowed the analysis of information from different spaces in different schools. The data were initially organised according to the approaches that had been used to produce them: i.e. as observation, interview or on-line investigation and inter-rater reliability was used. We then analysed the coded information in terms of location (e.g. in classes/school or outside [and where]). We discussed the data extracts, the main concepts that we felt were emerging and their interpreted meanings, read each other's fieldwork, and then recoded and regrouped the data in relation to how family participation was generally constructed and motivated in different schools and how teachers and families felt about the need to encourage family participation. We wanted to try to explain the mechanisms of production (construction) behind the different organizational format.

\section{Results}

In a context where the family participation is mainly based on the information and the collaboration with the school (Vigo-Arrazola and Dieste-Gracia 2019) one common important point across different schools concerning the issue of parental inclusion and involvement concerned how participation of families was conducted and motivated, and another related to the 
level of acceptance of the worthwhileness of the participation of families for shaping educational exchanges. During the research process we could see how the aesthetic practices of subjectivation allowed teachers to see a space for reflecting about the configuration of the space (Foucault 2009) against what had previously been imposed on them and when obtaining information from teachers and parents we experienced some differences in the different schools, and we experienced some dilemmas too, related to the limitations of the research and some data imbalance. Teachers participated in an active way facilitating data collection. Participant observation in classrooms and into different collective meetings with parents gave us rich possibilities to obtain information and to see changes in observed situations. However, from some parents, we experienced some difficulties to communicate in some informal conversations and interviews because of their low level of Spanish language. There were also difficulties related to the virtual interaction through the net in the peri-urban school because platforms were not present. 'Many families were in a disadvantaged situation socially and economically. They didn’t have a computer or any possibilities of getting one' said the headteacher. Another question was in the urban school, when only a group of families closer to the parents association were participating. However, the information from the participant observation was very rich.

The aesthetic practices of parental involvement in these senses showed a different configuration in each space, in each school, which each comprised a culturally and linguistically complex educational context that offered its own particular possibilities, experiences and challenges (Vigo-Arrazola and Soriano-Bozalongo 2015; Vigo-Arrazola and Dieste-Gracia 2019). The teachers at each of the schools accordingly highlighted a different way of communicating with parents and special practices and feelings that are involved in working in these contexts. Sometimes the teachers described concentrating on concrete conditions of the 
space they were acting within and on the value of considering the families and the local traditions, associations and knowledge in an interactive way. The aesthetic dimension, in this sense, is the appreciation and use of space that makes and that hides possibilities from us. Teachers and parents together developed different approaches to enhancing family participation. The different ways of creating participation are presented below.

\section{Inquiring about students and their families}

Inquiring about students and their families was most clearly articulated in practices at the periurban school. In it, teachers focused on researching and discovering the values, beliefs and customs of the families both inside and beyond school boundaries, so they could place them both 'within the range of regular curriculum activities' and in relation to the experiences and knowledge of the local community (Teacher school).

One teacher is asking about the origin of the children's names. Children from Morocco, Rumania or from the town (gypsies and no-gypsies) are investigating about their name. The teacher says that they will work in Spanish language and in Social Sciences from this theme. (Fieldnotes)

Teachers acted in this sense in an opposite way to the teachers described in the research by Bergnehr (2015). As considered by Foucault (2009), as subjects they tried to overcome the asymmetries established by constituting themselves as co-subjects that acted on the bases of an historical ontology and in relation to personal enactments of professional ethics. They were inquiring about their students and their families in order to connect with them and to connect them to the curriculum to try to close gaps between school and their life. They found new visions and new ways of being. Teachers investigated the families' experiences through various means. 
Today a teacher is asking families to write letters to school suggesting things they could do, and then by involving them in subsequently related curriculum and/ or extra curriculum activities they tried to create as an aesthetic feeling of community in their school. She is researching about the family culture in the classroom too during a 'free text' activity that was undertaken by students. This activity had emerged during the participant observation through the interaction between the researcher and the teacher, and the teacher often used it and generated a project in this school, carried out by all the teachers and parents together. They began to develop a dialogue about change and, from this dialogue, ideas about a research project that they could own together began to take shape in a way that in the words of a Moroccan mother 'really changed their feelings about school and their own place and value in relation to their children's learning there' as a way to confront history as opposed to just reacting to it (Denzin, 2018). Interaction was carried out continually during the research process and at the end. We weren't passive as researchers. We were observing what teachers and families were doing and we listened to them as conscious and reflective agents. (Fieldnotes Peri-urban school)

The interaction between the participants in the above example formed a space where teachers, families and researchers generated dialogue as a basis for rethinking and re-forming lived social relations and as a means to create locally owned and place specific solutions to experienced education problems.

The cultural traditions of families were presented through the preparation and development of a round-table activity that involved parents from different countries and cultures and other relatives. It was entitled 'Tell me about yourself so I can get to 
know you'. The idea was initiated by teachers and parents from inspiration from work by the ethnographic film director Eugenio Monesma. (Peri-urban school. Field notes). In a preparatory session to this event, we observed how 3 Spanish teachers, 1 French teacher and 6 mothers from different countries and cultures are organizing a roundtable and deciding what subjects about costumes and culture would be sensible to include and why. After a discussion process in which families and teachers raised different issues, they decided that the Guinean mother would talk about the importance of a particular cotton plant from her country (ecology, geography, economy), the mum from Peru would talk about Christmas in her country (culture, society), whilst the Moroccan mother would describe weddings in a region from Morocco (culture, society), close to the mountains, the Roma mother would speak about Roma education (family, culture, society), a Spanish teacher would explain the tradition of the "Tronca" in Aragón (culture, local values) and a French teacher would talk about Easter in France (culture, society, religion). A poster announcing the event is in the school and in different social nets. Two weeks later we observed how the roundtable was carried out in the school hall /.../ The session is open to everyone of the town. The moderator and six people present a tradition or custom from their country. First, the moderator explains the history of migrations and he introduces all the panellists and they give their presentation. After that, a discussion between them and the audience of 60 or 70 people begins /.../ Families from the school and people from social services that work with minorities, street educators are the audience are present. There are few local original people of the town, but many African women'. Thus, people from different countries were involved and many of them, particularly 
some of the Roma, intervened with questions and comments /.../ One woman from Guinea is speaking for five minutes and is helped by a translator. The moderator makes questions about Africa but none of them intervene. A Roman mother talks about Roma education, highlighting respect for the elderly and respect between different ethnic groups. A neighbor of the Moroccan neighborhood, who speaks of his friend "Susi" who is of gypsy race, gave an example of coexistence providing a very rich reflection on how it is good to follow and respect the customs, but always taking into account that society, people and needs change so we must also evolve. Although there is a very large number of African women, none of them intervenes. All interventions remain very attentive.

A father of Nicaraguan nationality (only person from South America of the public), highlights the importance of continuing to maintain the traditions and that this depends on each of us. He gives great importance to instill in children respect towards the elderly. They speak very proudly of their country The moderator closes the debate, noting that such activities are important as they help families from different cultures to share their experiences with the school and spread awareness of the characteristics and concerns of each cultural group. (Peri-urban school Field notes)

The effects of the roundtable on the teachers were registered later in interviews. They were very positive about their experiences (the aesthetic practices and ethics) of what had gone on and of what they had learned. 
It felt good and I learned a lot and now I'm looking forward to getting to know the families’ culture even more, because otherwise I cannot understand them and then I cannot understand my students either... (Interview teacher Peri-urban school)

Teachers at this school emphasised thus not just the value but also the need to meet families outside of institutional boundaries to break down feelings of marginalisation and to create an aesthetic ethical sense of together-ness. They cared about the families' interests and concerns and wanted to know about them and understand them and they also wanted them to get to want to know the school and to feel part of it. Some teachers arranged parental meetings outside of normal school hours and in a more comfortable context for the family to these ends.

Last weekend I went to an African party that took place near the school. The African families wanted to open a small school in Senegal and all their families were there. I met three families of my class. The party is a small point of reference that can be considered for the class curriculum. (Interview with teacher Peri-urban school)

This sense of feeling for the families did not just happen by itself. It came from an active process of familiarisation and aesthetic experience that gradually broke down boundaries and notions of otherness. But once borders had been broken down the teachers wanted to work more from the bottom up together with the families in developing the education of the children and the levels of learning in the community. It felt right to do this they said and they talked about the value of getting to know families from the area and how this had helped to change their professional ethics and habitus. A teacher of the peri-urban school tells us: 
My way of thinking about the participation of families has changed as has my way of feeling, acting and talking about their work. I now try to discover about the lives children lead in order to help them to participate in school better and to learn more effectively. (Teacher peri-urban school)

Put in another way, inquiring about children and their families hadn't changed the teacher's professional ambition, this was still to create an environment for participation to improve learning. But, in an aesthetic sense the parents' social capital was now seen as valuable on its own terms and in its own right and teachers also tried to influence this through contact with families and by creating opportunities for them to interact with each other with a hope that together they could influence pupils and help them to subsequently improve their learning. During the research process we could experience how through interaction between researchers, teachers, families and students the normal resistance to togetherness was broken down in an educational context through mutually valued aesthetic practices and experiences (Lareau 2000). Bouakaz (2007), Theodorou (2008) and Bergnehr (2015) have all remarked on the potential value of this kind of approach. So too have Crozier and Davies (2007), Garreta and Llevot (2011) and Lundberg (2015), who all highlighted the value of a space for the shared expression of emotions, closeness, feelings, reflection, the acknowledgement of others, and of developing a community spirit. However, more cautiously these and other authors (such as Beach 2017) recognised too that such recognition and changes in the local curriculum also risk creating other problems, particularly with respect to formal learning. As emphasised by the Organic Education Act of 2013. The formal curriculum has spaces for some local autonomy but not at the expense of official knowledge and its ideological orientation, interests and modes of cultural reproduction. Official knowledge is thus formally related to the function of the school as an 
official agency of power, regulator of the relation between inner and outer contexts, and a generator of guiding principles to the production of the texts adequate to each of them (Bernstein 1990; Beach 2008).

\section{Recognising pupils' family and environmental conditions}

Recognising Rumanian, Moroccan and local pupils' family and environmental conditions and the value of aesthetic practices of subjectivation was found particularly at the rural school and the teaching team offered support to the families to facilitate their participation. Similarly to teachers

at the peri-urban school, the teachers in the rural school organised projects and workshops linking the families' cultures and environment with the curriculum, thereby showing respect and appreciation of community members in the teaching process. But they also created innovations around aspects of the local environment and local production. They incorporated for instance professionals connected with mines in the local area and supermarkets in the village, and in one case the teacher moved the location of a Mathematics class to the small local supermarket, where one of the parents of a former pupil was employed, in order to illustrate how the local environment both needed and provided skilled and competent workers. These kinds of activities developed a curriculum content that integrated areas of Language, Mathematics and Natural Sciences, within the context of the students' lives by weakening the boundaries that normally operate to insulate the work and content of the school from that of the immediate environment. They were described by the headteacher as follows.

This year in Mathematics, we have worked with decimals in a supermarket. There, they explained how to perform an inventory, what expiry dates were and mean, how the cash register works, how purchases are made and how receipts are used to calculate change. (Head teacher Rural School) 
This kind of weakened classification of the curriculum was used as a means of integration of parents and other family members in school activities. But families were also recognised when teachers arranged workshops on different topics. During an interview, a Moroccan mother who had been living in the village for five years, told us that 'a teacher asked me to do an Arabic reading workshop with the children. I did it with a friend. My friend read in Arabic and I translated it' (Mother Rural School). In this case, the culture of minority families was directly present at the school. In other occasions, the school opened its doors to all the families and teachers together and recognised their different cultures and values.

Today is 'open door' day. There are cooperative games with balls, ropes, a parachute, and a cake contest. Firstly, children, mothers and grandmothers start arriving with cakes. We can see the participation, the interest and effort families put in /.../ The first and second prizes are cakes made by two Arabian families and the third is a cake made by a Spanish family. (Rural school Field notes)

The teachers attributed not only emotional but also educational value to the practices carried out with families, and they regularly highlighted in interviews with us how these activities 'helped to make learning into a more culturally significant experience and enjoyable enriching event' (Teacher Rural school). Esteban-Guitart et al. (2012) have also previously presented the value of events like these and, as did the teachers in the present investigation, they expressed how they recognised the value of introducing the experiences of the families into the school.

- Children could learn to recognise value in their cultural experiences and learn from the family in relation to their own education when 
- Parents presented information from a more emotional perspective and this is more motivating for the pupils

- Families felt valued and recognised

- The children were afforded opportunities through this that could help them to recognise and value family culture, and be creative in school at the same time

These points were expressed by teachers and pupils. But they were also expressed by family members too.

The parents, local and from abroad, 'wanted to come to the classroom to talk about their different experiences and the teachers facilitated the participation of everyone so that they felt recognised by the school' A father from the village said that 'it is important that children know our past’. (Rural school field notes)

Constructive relationships between families and schools were however also important and necessary as an ongoing aesthetical construction (Foucault 2009). As within the new concept of an open school for community involvement discussed in the previous section, the families of Moroccan and Rumanian origin and also those whose parents were born in the village were involved in the classroom and other parts of school-life, as part of a broader development of local cultural and (vertically bonding and bridging) social capital that was based on a fundamentally aesthetic foundation. Moreover, by incorporating their own class cultural inheritances and activities as well as local artefacts from the immediate environment and the local community in curriculum content. 
There also was no doubt in their minds that the pupils learned things from their engagements but teachers are also able to imbue the learning process with an important affective value. Pupils learned to count, speak Spanish, to make recipes, to overcome problems of verbal communication and to bake and make sweets and their self-confidence seemed to improve. They seemed to become more outward going and less shy and reserved. (Rural school Field notes)

Certain spatial characteristics of the rural school seem to have been highly significant here. For instance, the headteacher knew the families and considered that Moroccan, Rumanian and local parents' social and cultural capital may be possible to incorporate and use together to develop content and support learning and that through contact with the school parents would exchange knowledge and develop their social and cultural capital further. A win-win situation could be created she said that could then further influence students to subsequently improve their learning and future life- and livelihood opportunities (Lareau 2000; Hill and Craft 2003). The staff at the school also supported this idea, and 'they worked hard to try to realise this vision through material investments of time, effort and resources' (Rural school Field notes).

We share this positive recognition related to the relevance of local knowledge. However we have also had to recognise that as with respect to the peri-urban school, the official school curriculum is still strictly about imposing and rewarding official knowledge and using the reproduction of this knowledge to reinforce a social hierarchy (Bernstein 1990), and that thus, although introducing different elements and incorporating external culture may help to restructure the politics of the classroom around emotions that may facilitate positive aesthetic relationships to the school through unconventional content and aesthetic experiences, this new progressivism will most probably not alone be able to challenge the status of powerful official knowledge, nor 
the dominant understandings about the pupils who become exposed to these kinds of progressive pedagogy. To be recognised as successful and valued learners outside the local school the pupils must also do well in terms of official performances and standard forms of measurement in comparison to other pupils (Beach 2017). This is a dilemma that isn’t always clearly communicated or immediately understood by to parents.

\section{Using environmental knowledge in school}

Using environmental knowledge in school was most obvious in relation to the school we have listed as an urban school. Here, the values and culture of the neighborhood were included through various projects and through activities that were conducted in collaboration with the families, for implementation directly in the classroom, or at home (Theodorou 2008). Local parents often participated as information agents in these activities, but also as facilitators, support persons and extra-curricula resources to replace textbook-only-learning. That is, the content focussed was official school content, but the framing of this official knowledge was, as the headteacher specified, shifted.

Only using textbooks limits the participation of parents, while working with projects as we do makes the possible participation of parents greater. And although this is not the methodology followed by all the teachers in this school, it is used by many of them. (Headteacher Urban School)

One example is the 4th grade teacher.

Children are presenting survey results that their parents have answered about the neighbourhood. Students pool the answers in small groups and make a list of needs, which will then be presented in a written formal letter to the Mayor. Natural Sciences, 
Language and Mathematics are involved. Parents are involved through the use of homework. (Urban School Field notes)

As in the rural school these activities break down the degree of insulation between content from the outside and the inside of the school, but unlike in the rural school, in the urban school this activity was not about recognising other values and cultural experiences as a way of broadening the curriculum. The activities were actually about reinforcing the learning of official knowledge. Sometimes activities were organised for all classes at once. In one of these cases, teachers used one or more of the local parks that were close to the school in the learning process to discuss concepts from biology and nature studies.

A project about the various city parks is ongoing. All the parents were asked to collaborate at home. Each academic grade has been allocated a particular park. Parents receive a list of tasks, like going to visit the park with the children, to take pictures, make comments about how to get to the park or if there is a playground there. Following the activity, one of the local fathers said that children viewed the activity as something positive 'because it is a project everyone is involved in'. (Urban school)

As one teacher said, 'paying attention to the neighbourhood makes it easier for children to learn as it sets the curriculum content within a more authentic context and allows families to more easily recognise the purpose of their participation'. The local environment can be used to replace the usual textbooks to give a more aesthetic foundation which admits knowledge 
communicated through the eyes and other senses, which the teacher described as 'often used with natural science, mathematics and art:

I think about the children's interests and the local spaces because it is much more meaningful to them and harder for them to forget what they learn. It involves them in being creative and producing something. It is less distant and abstract than reading from a book and parents can become involved in school activities. Not just in homework. (Teacher Urban school)

In line with Bouakaz (2007), Theodorou (2008) or Bergnehr (2015), the teachers here have all remarked that they recognised the value of the acknowledgement of others and of developing a community spirit (Crozier and Davies 2007; Garreta and Llevot 2011; Lundberg 2015) but the involvement doesn't stretch to making changes in the local curriculum that risk creating problems with respect to official curriculum knowledge. At the urban school in the context of competition for reputation and students, rather than trying to create broader platforms of involvement and changed social relations spaces for parental involvement were created within the space of the official curriculum. Parents were used as motivators and assistants on trips and activities, as in the other schools, but the spatial characteristics of the school also generated aesthetic subjectivations where a new feature of contemporary schooling stemming from the neoliberal agenda for education become visible.

This school was a middle class school on the edge of a large city where there was competition for pupils and over performances with other schools, and where parents knew they had choices and other schools to turn to. And these spatial features created two strong demands on schools and teachers as professionals, according to the teachers and the head teacher. The first 
was the need for children to do well competitively in school by being able to reproduce official knowledge. The second was to make pupils and parents contented as consumers. This is also what parents want, according to the headteacher. They want their children to be 'both happy and successful in school' and accordingly importance was placed both on the knowledge that was to be learned in terms of its exchange value, and that this was communicated and assessed in a relaxed and enjoyable way to help to create successful and happy learners and satisfied parents. The professional interest is constructed around consumer satisfaction in this sense and what was important to this scenario was that the school was surrounded by other schools that competed over pupil recruitment.

Competition created a subjectivation of consumer satisfaction that was conditioned by a very different set of contingent circumstances to those in the other two schools. It affected professional habitus, parental involvement, and what activities were deemed valuable and became reinforced in school and as praxis (the professional aesthetic) and there is a clear logic too to all of this too. School reputations and performances are important for the school brand, the school brand was key to recruitment, and there was a sense of mutual instrumentalism as the value sets of the teachers (as official representatives of the school) and the parents overlapped in terms of wanting happy and successful learners. Relationships in education are built from particular material situations and experiences of them (Bouakaz 2007).

\section{Discussion}

Using ethnographic research, we have examined how three schools organised parental participation in different ways, some of which sometimes challenged the traditional view of teachers as the experts and parents (particularly from lower-class backgrounds) as educational problems not solutions. In these conditions parents could become partners and together in 
partnerships with teachers they could challenge the status quo of teachers as experts and parents as problematic and fallible (Beach, 2017). However, we also wanted to show how teachers in different contexts and with different populations developed different aesthetic practices of subjectivation (Foucault 2009) in the educational system and thus we have also focussed on the interaction between researchers and research subjects in concrete terms in particular concrete aesthetic circumstances to allow us to see how teachers are often forced and able to both resist and challenge reproduction in the school, by recognising the values of the families and 'following' the flow of events as they unfold. They started process of reflection on action and carried out reconstructions that recognised the values of the families and the environment. In terms of Foucault, the aesthetic practices of subjectivation allowed them to reflect about and reconfigure interaction against what has been imposed (Foucault 2009) and by giving them space as agents in the research we were, as researchers, also able to identify, document and analyse these actions . It is possible to see the construction of resistance through subjectivity.

As researchers in the different schools we worked as ethnographers within an actornetwork examining and analysing the aesthetics of practices involving teachers, parents and pupils in three schools. A common point was that open-mindedness and thinking of the other were present at all the sites, and that parents were seen as an important value, but that this value was seen in three different and highly contextually influenced ways. Community needs were stressed in one context. The need of the school was stressed in another. And the effects of competition and demands of consumer satisfaction in the third. Situations and events outside school thus had a critical bearing on events inside it and due to these contingent features, different ways of working developed that shaped the aesthetic of professional action and the conditions for family participation differently. 
In the peri-urban and rural schools, the aesthetic practices of subjectivation allowed the development of constructivist teaching methodologies in classrooms that allowed more room for families in the development of teaching-learning practices (Vigo-Arrazola and SorianoBozalongo 2015) and all the parents were able to become involved in the school curriculum and interactions; including even those that were connected to planning and delivery. In the urban school the aesthetic practices of subjectivation meant that the parents contributed to the delivery and learning of official knowledge designed by the school and its teachers as the market context aesthetically enhanced conditions of performativity and competition. Teachers and parents (and above all the headteacher) were aware that there were other schools in the area that were competing for good results in official tests and parental attraction for pupil recruitment.

Keeping the school open was the challenge in the small rural school and the peri-urban school. These schools were considered as a source of added value for the community and its members, and collaboration was easy to build in this respect. These schools were under threat of closure through size at the rural school and low-performance levels at the peri-urban, and teachers with the help of community members (including often mainly parents) concentrated resources on creating good pedagogical conditions and dynamic relationships in a dialogue of equals as a way of maintaining a stable population. This was the vital aesthetic. As Bouakaz (2007), Åberg-Bengtsson (2009) and Beach (2017) have suggested people in rural and many poor peri-urban communities often committed to their school and very creative in trying to find ways to keep it open and in the peri-urban and rural schools teachers and leaders developed a social commitment toward the community that facilitated attempts to incorporate family knowledge to improve teaching and learning practices (Crozier and Davies 2007; Beach 2017). They were politically committed to the school in a seriously socially challenged neighbourhoods with 
multidimensional poverty and engaging with families was a way to show value and empower the community.

\section{Conclusions}

The article set out to explore practices of parental involvement in peri-urban, rural and urban schools and the experiences of parents and teachers there. It shows that parental involvement is developed in schools in different ways in a context of needs arising in relation to the aesthetic of experiences in local conditions and the characteristics of the geographic spaces the schools belonged to. Some consistent points emerged. One was that parental involvement was never an end in itself. There were always other "ends”, and they were connected to spatial characteristics and cultural differences in the local catchment area in terms of its location and the makeup of its population with respect to social class, racial and linguistic mix, transnationalism. The commitment of teachers to the local communities they were serving also seemed to be significant, as did their familiarity with the local context and its history and aesthetic professionalization was thus configured differently in the different contexts.

The article describes different aesthetic practices of parental involvement as an element of this aesthetic professionalisation. But these things need further research on how life in school through the curriculum and from the point of view of teaching is focused on the students, their experiences and their life outside the school in different ways for different reasons, and how knowledge of local spatial dynamics can support teachers and parental participation for the learning success of pupils in school. The work takes as a reference the pedagogical practice of teachers who question their own practice and the effects this entails in different spaces and contexts, and how it can inform the process of forming the aesthetic experience of subjects when 
they (and we) try to understand and deal with the complexity of the current field of education in order to change it.

\section{References}

Åberg-Bengtsson, L. 2009. "The smaller the better? A review of research on small rural schools in Sweden." International Journal of Educational Research 48 (2): 100-108. doi: 10.1016/j.ijer.2009.02.007.

Beach, D. 2008. “The paradoxes of student learning preferences.” Ethnography and Education 3 (2): 145-159. doi: $\underline{10.1080 / 17457820802062375}$

Beach, D. 2017. "Whose justice is this! Capitalism, class and education justice and inclusion in the Nordic countries: race, space and class history.” Education Review 69 (5): 620-637. doi: $\underline{\operatorname{org} / 10.1080 / 00131911.2017 .1288609}$

Bergnehr, D. 2015. “Advancing home-school relations through parent support?” Ethnography and Education 10 (2): 170-184. doi: org/10.1080/17457823.2014.985240

Bernstein, B. 1990. Class, Codes and Control, Vol. 4: The Structuring of Pedagogic Discourse. London: Routledge.

Bouakaz L. 2007. "Parental involvement in school: what hinders and what promotes parental involvement in an urban school.” PhD diss. Malmö: Lärarutbildningen, Malmö högskol.

Crozier, G., and J. Davies 2007. "Hard to reach parents or hard to reach schools? A discussion of home-school relations, with particular reference to Bangladeshi and Pakistani parents.” British Educational Research Journal 33 (3): 295-313. doi: 10.1080/01411920701243578

Denzin, N. K. 2018. Staging resistance: Theatres of the oppressed. In The Handbook of Ethnography of Education, edited by Dennis Beach, Carl Bagley and Sofia Marques da Silva, 375-402. London and New York: Wiley. 
Edwards, R., and P. Alldred. 2000. “A typology of parental involvement in education centring on children and young people: Negotiating familialisation, institutionalisation and individualism.” British Journal of Sociology of Education 21 (3): 435-455. doi: $10.1080 / 713655358$

Eisenhart, M. 2017. “A Matter of Scale: Multi-scale Ethnographic Research on Education in the United States.” Ethnography and Education 12 (2): 134-147. doi: 10.1080/17457823.2016.1257947.

Escardíbul, J.O., and A. Villaroya. 2009. “The inequalities in school choice in Spain in accordance to PISA - data.” Journal of Education Policy 24 (6): 673-696.

Esteban-Guitart, M., J., Oller, and I. Vila. 2012. “Connecting school, family and community through funds of knowledge and identity. A case study of a moroccan origin family.” [Vinculando escuela, familia y comunidad a través de los fondos de conocimiento e identidad. Un estudio de caso con una familia de origen marroquí.] Revista de investigación educativa 10 (2): 21-34.

Foucault, M. 1991. Microphysics of power [Microphysics of power]. Madrid. La Piqueta.

Foucault, M. 2009. The history of sexuality 1. The will to knowledge. [Historia de la sexualidad 1. La voluntad del saber.] Buenos Aires: Siglo XXI.

Fox, N. J., and P. Alldred. 2018. New materialism. In: Atkinson, P.A., Delamont, S., Hardy, M.A. and Williams, M. (eds.) The SAGE Encyclopedia of Research Methods. London: Sage. (1) (PDF) New Materialism. Available from: https://www.researchgate.net/publication/320016117_New_Materialism [accessed Jun 15 2019].

Garreta, J., and N. Llevot. 2011. "Immigrant families and the school in Spain: dynamics and factors 
that influence their relations.” Journal of Educational, Cultural and Psycological Studies, no. 4: 47-67. doi: $10459.1 / 47004$

Hill, N. E., and S. A. Craft. 2003. "Parent-school involvement and school performance: Mediated pathways among socioeconomically comparable African American and Euro-American families.” Journal of Educational Psychology 95 (1): 74. doi: 10.1037/0022-0663.95.1.74

Lareau, A. 2000. Home advantage: Social class and parental intervention in elementary education. New York: Rowman \& Littlefield Publishers.

Lundberg, O. 2015. On Cultural Racism and School Learning: An Ethnographic Study. Göteborg: Acta Universitatis Gothenburgensis.

Organic Education Act 8/2013, 9 December. 2013. on the Improvement of the Quality of Education (LOMCE). Boletín Oficial del Estado, 295, 2013 December 10.

Troman, G. 2006. Editorial. Ethnography and Education 1 (1): 1-2.

Theodorou, E. 2008. “Just how involved is ‘involved’? Re-thinking parental involvement through exploring teachers’ perceptions of immigrant families’ school involvement in Cyprus.” Ethnography and Education 3 (3): 253-269. doi: 10.1080/17457820802305493

Tveit, A. D. 2014. "Researching teachers' and parents' perceptions of dialogue.” International Journal of Inclusive Education 18 (8): 823-835. doi: 10.1080/13603116.2013.841296

Vigo-Arrazola, B., and B. Dieste-Gracia. 2017. "Contradictions in inclusive education through a multi-scalar study.” [Contradicciones en la educación inclusiva a través de un estudio multiescalar.] Aula Abierta 46: 25-32. doi: https://doi.org/10.17811/rifie.46.2017.25-32

Vigo-Arrazola, B., and B. Dieste-Gracia. 2019. "Building virtual interaction spaces between family and school." Ethnography and Education 14 (2): 206-222. doi: $\underline{10.1080 / 17457823.2018 .1431950}$ 
Vigo-Arrazola, B., and J. Soriano-Bozalongo 2015. "Family involvement in creative teaching practices for all in small rural schools.” Ethnography and Education 10 (3): 325-339. doi: $\underline{10.1080 / 17457823.2015 .1050044}$

\section{Funding details:}

This work was supported by the [Sub-programme of Fundamental Research Projects of the Ministry for Economy and Competitiveness], under Grant [EDU2012-32657] 2012-2015. 